\title{
Structural and Chemical SEM Study of Carious Human Tooth
}

*Tiznado Orozco Gaby Esthela **José Reyes-Gasga

* Facultad de Odontología, División de Estudios de Posgrado, UNAM. Circuito Exterior s/n 04510 Ciudad Universitaria. D. F.

**Instituto de Física, UNAM, Circuito exterior s/n 04510 Ciudad Universitaria. D. F.

Dental caries is an infectious disease, in which microbial fermentation of dietary carbohydrates leads to localized dissolution and destruction of teeth (Fig. 1). It is also considered as a transmissible disease ${ }^{(1)}$. According to the Prevention and control of Disease Center, this disease is one of the most prevalent, the Mexican people reaching levels of around $70 \%$ of the inhabitants.

The bacterias associated to carious lesions are $S$. Mutans, Lactobacillus and Actinomyces viscosus principally (Fig. 2). Pathogenic bacterias produce lactic acid from the effect of fermentation of carbohydrates; these acids easily dissolve the hydroxyapatite crystals, main component of the inorganic material that conforms the teeth. After this dissolution, begins a degradation of its organic material $^{(2)}$.

This infectious disease produces lesions that may affect enamel, dentin, pulp and cementum. Early caries lesion presents a greater porosity in deeper layers than in the superficial layer of enamel. The so-called "white spot" lesion is a dynamic lesion which is subjected to the changes that occurs in the oral cavity; it can regress, stabilize or progress to a more serious disease ${ }^{(3)}$.

It is important that the dentist understand the tissue changes that occurs with the carious process in teeth and that are likely to take place during lesion development, even more if a the carious lesion has progressed until a stage where the tooth requires restorative process ${ }^{(4)}$.

In this work we present the structural and chemical study of teeth with caries obtained with the scanning electron microscope (SEM). The specimen were examined with the microscope JEOL 5600 at high and low vacuum. This microscope has an NORAN x-ray energy dispersed spectroscopy (EDS) equipment attached.

\section{References:}

[1] Griffen, Ann, et al. Dental Caries. An infectious and transmissible disease. Pediatric Clinics of North América. Oct. 200; 47(5).

[2] Tanzer, Jason. Salivary and plaque microbial test and the management of dental caries. Journal of Dental Education. Nov 1997; 61(11): 866-74.

[3] CM, Miani, et al. Clinical observations on the nature early caries. A study with scanning electron microscopy. Minerva Stomatol. Apr. 2000; 49(4): 139-47.

[4] L. Bjørndal, et al. Pulp-dentin biology in restaurative dentistry. Part 4: Dental caries, characteristics of lesions and pulpal reactions. Quintessence Int. Oct. 2001; 32(9): 717-36.

[5] Acknowledged. This research is tanks help following people: P. Mexía., R. Hernández, C. Flores, M. Aguilar, J. Cañetas, S. Tehuacanero, I. Puente Lee, C. Zorrilla, C. Magaña, L. Rendón, A. Sánchez. This work was supported by DGAPA-UNAM with the project IN-104902. 


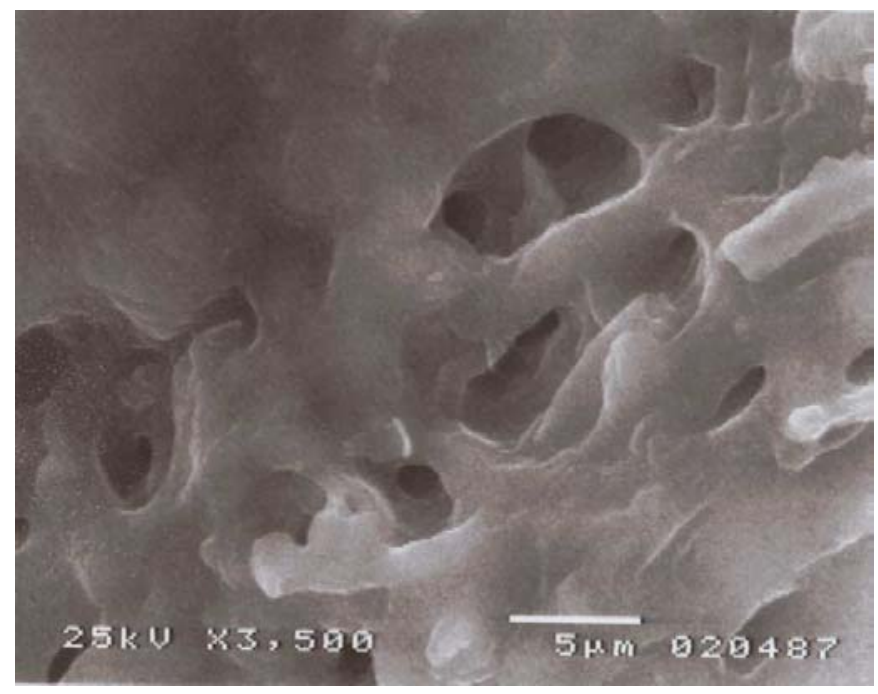

figure 1. SEM image of dentinal tubules from a section of teeth affected with dental caries.

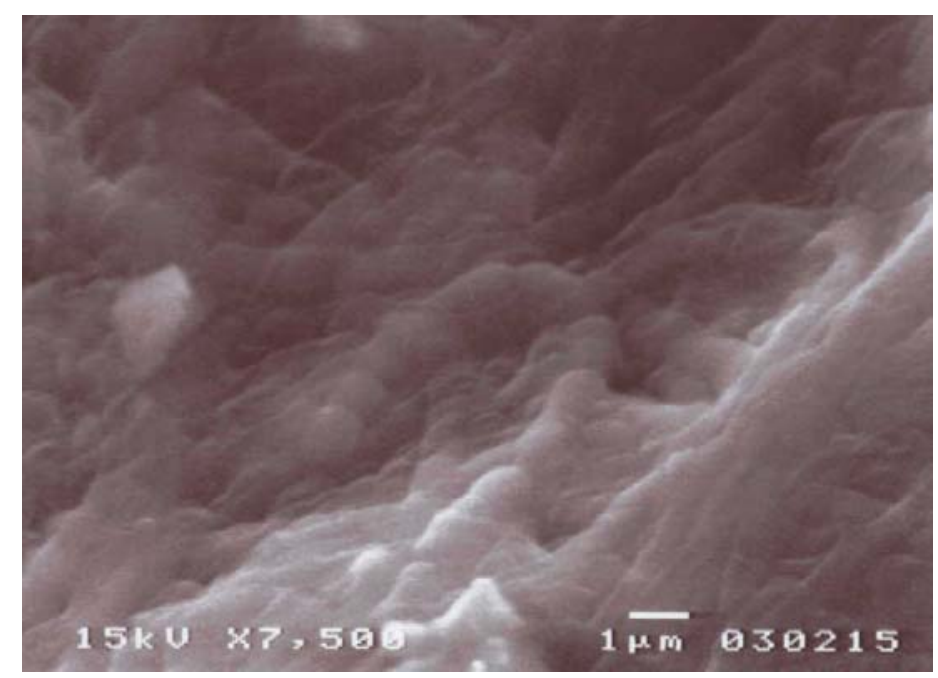

Figure 2. SEM Image of a premolar with dental caries, which present a structure of coccus-like bacteria. 